\title{
PENGARUH PRILAKU TERHADAP KESELAMATAN PENGEMUDI SEPEDA MOTOR
}

\author{
Abadi Sastrodiyoto, SH,MH \\ Dosen STTD \\ Jl. Raya Setu No. 89, Bekasi \\ Telp./Fax : (021) 8254640
}

\author{
Ir. Santausa Purnama S,MM \\ Dosen STTD \\ Jl. Raya Setu No. 89, Bekasi \\ Telp./Fax : (021) 8254640
}

\author{
Purwatiningsih, SH,MM \\ Dosen STTD \\ Jl. Raya Setu No. 89, Bekasi \\ Telp./Fax : (021) 8254640 \\ Subarto, ATD, MM \\ Dosen STTD \\ J1. Raya Setu No. 89, Bekasi \\ Telp./Fax : (021) 8254640
}

\begin{abstract}
In fact, motorbikes in terms of technical and safety, only intended for short-distance transportation or precisely on an environmental road that is not congested with traffic. But in Indonesia today, this is not considered and motorbikes are often used to exceed the load capacity and distance, even to travel a distance of hundreds of kilometers in the Eid transport period. In addition, the compliance and politeness of motorbike users, especially in big cities is very alarming, resulting in tremendous congestion and chaos. This, resulting in the number of accidents that occur on the streets. The cause of traffic accidents from human factors, especially for motorcycles, based on the results of a survey conducted, obtained data that the knowledge I compliance of motorcycle drivers regarding traffic signal control devices (APILL) or traffic control (traffic light) has only reached $78 \%$ of 175 respondents
\end{abstract}

Keywords: Driver Behavior, Motorcycle, Safety

\begin{abstract}
ABSTRAKSI
Sejatinya sepeda motor dari segi teknis dan keselamatan, hanya diperuntukan untuk angkutan jarak pendek atau tepatnya di jalan lingkungan yang tidak padat arus lalu lintasnya. Namun di Indonesia saat ini, hal tersebut tidak diperhatikan dansepeda motor sering dipergunakan melebihi kapasitas muatan dan jaraknya, bahkan untuk menempuh jarak yang ratusan kilo meter
\end{abstract}


pada masa angkutan Lebaran. Di samping itu, kepatuhan dan kesantunan pengguna sepeda motor, khususnya di kota-kota besar sangat memprihatinkan, sehingga terjadi kemacetan dan kesemrawutan yang luar biasa. Hal tersebut, berakibat pada jumlah kecelakaan yang terjadi di jalanan. Penyebab kecelakaan lalu lintas dari faktor manusia terutama untuk sepeda motor tersebut, berdasarkan hasil survei yang dilakukan, diperoleh data bahwa pengetahuan/kepatuhan pengemudi sepeda motor mengenai alat pengendali isyarat lalu lintas (APILL) atau pengatur lalu lintas (traffic light)baru mencapai $78 \%$ dari responden sebanyak 175 orang

\section{Kata Kunci : Prilaku Pengemudi, Sepeda Motor, Keselamatan}

\section{PENDAHULUAN}

Latar Belakang

Perkembangan angkutan di Indonesia dewasa ini dari segi jumlah kendaraan yang diproduksi dan beroperasi di jalan meningkat sangat tajam. Sejatinya sepeda motor dari segi teknis dan keselamatan, hanya diperuntukan untuk angkutan jarak pendek atau tepatnya di jalan lingkungan yang tidak padat arus lalu lintasnya. Namun di Indonesia saat ini, hal tersebut tidak diperhatikan dansepeda motor sering dipergunakan melebihi kapasitas muatan dan jaraknya, bahkan untuk menempuh jarak yang ratusan kilo meter pada masa angkutan Lebaran. Di samping itu, kepatuhan dan kesantunan pengguna sepeda motor, khususnya di kota-kota besar sangat memprihatinkan, sehingga terjadi kemacetan dan kesemrawutan yang luar biasa.

Hal tersebut, berakibat pada jumlah kecelakaan yang terjadi di jalanan, yang tiap tahunnya cukup banyak. Berdasarkan data yang diperoleh dari Korlantas Polri bahwa pada tahun 2014 tercatat jumlah kecelakaan lalu lintas sebanyak 95.906 kasus, 2015 tercatat sebanyak 98.970 kasus, dan tahun 2016 meningkat menjadi sebanyak 105.374 kasus, namun pada tahun 2017 turun menjadi sebanyak 98.419 kasus. Untuk jumlah korban sebanyak 258.775 orang pada tahun 2016 dan pada tahun 2017 turun menjadi sebanyak 249.763 orang

\section{Identifikasi Masalah}

Berdasarkan latar belakang tersebut di atas, dapat didentifikasi masalah sebagai berikut:

1. Berbelok tanpa sein dan berbelok kiri dengan memberi sein sebelah kanan.

2. Membawa penumpang sepeda motor lebih dari satu atau membawa barang berlebihan 
3. Berkendara sambil telepon atau membaca/menulis SMS atau mengobrol (tidak konsentrasi).

4. Tidak mepunyai SIM C untuk mengemudikan sepeda motor.

5. Memperoleh SIM C tidak sesuai prosedur.

6. Mengemudikan sepeda motor tidak memakai helm yang memenuhi SNI, sepatu, jaket yang dapat memantulkan cahaya, dan sarung tangan pelindung.

7. Mengemudikan sepeda motor tidak sesuai dengan tata caramengemudi yang baik/selamat atau tidak taat terhadap aturan lalu lintas, karena tidak memahami mengenai alat pengendali isyarat lalu lintas (APILL)/traffic light, rambu lalu lintas, dan marka jalan.

8. Mengemudikan sepeda motor dengan kecepatan tinggi dan ceroboh, sehingga dapat mencelakakan diri sendiri atau orang lain.

9. Mengendarai sepeda motor sambil merokok.

10. Mengendarai sepeda motor dengan arogan.

\section{Rumusan Masalah}

Berdasarkan jumlah kecelakaan lalu lintas yang terjadi dengan jumlah korban jiwa yang cukup tinggi tersebut, maka perlu dilakukan penelitian bagi pengguna sepeda motor, dengan rumusan masalah sebagai berikut :

1. Bagaimana pengetahuan dan pemahaman Pengendara sepeda motor tentang alat pengendali isyarat lalu lintas (APILL) atau lampu lalulintas, rambu lalu lintas, dan marka jalan?

2. Bagaimana tingkah laku (sikap) pengendara sepeda motor selama berkendara?

3. Bagaimana caramemperoleh SIM untuk mengemudikan sepeda motor?

\section{Tujuan Penelitian}

Tujuan penelitian ini adalah untuk mengetahui pengaruh perilaku atau tingkah laku terhadap keselamatan pengemudi sepeda motor dan guna meningkatkan pengetahuan yang akan dipergunakan untuk : 
1. Bahan penyuluhan mengenai keselamatan berlalu lintas, mengingat sejak 2015 STTD setiap tahun melakukan penyuluhan keselamatan tersebut bagi pelajar SLTA (2018

2. sebanyak 1.000 orang siswa dan ada usulan lagi sebanyak 1.000 orang siswa pada Desember 2018). Di samping itu, STTD juga diberi tugas untuk melaksanakan Diklat Pemberdayaan Masyarakat, yang salah satu substansinya, yaitu sosialisasi keselamatan lalu lintas (termasuk kecelakaan sepeda motor);

3. Bahan masukan kepada pemerintah dalam menetapkan kebijakan di bidang pembinaan bagi pengendara sepeda motor.

4. Bahan masukan bagi pengemudi sepeda motor khususnya dan masyarakat pada umumnya.

\section{METODOLOGI PENELITIAN}

\section{A. Desain Proses Penelitian}

Lokasi kegiatan direncanakan di wilayah Kabupten Bekasi dan selanjutnya kegiatan ini direncanakan dibagi dalam empat (4) tahapan yang dimulai dari identifikasi masalah, pengumpulan data, pengolahan data dan keluaran (output), yang secara rinci dapat dijelaskan sebagai berikut :

1. Identifikasi masalah

Pada tahapan ini akan diperoleh berbagai masalah dari wilayah studi yang selanjutnya untuk mempermudah penyelesaian penelitian, dibuat perumusan masalah yang diambil dari batasan permasalahan yang akan diteliti.

2. Pengumpulan data

Pengumpulan data ini meliputi pengumpulan data sekunder yang diperoleh dari instansi terkait seperti Dinas Perhubungan Pememerintah Kabupaten Bekasi, Kepolisian RI atau Polres Bekasi, dan Ditjen Perhubungan Darat, sedangkan data primer diambil dari survei melalui pengisian kuisioner dan/atau wawancara langsung di lapangan terhadap pengemudi sepeda motor.

Setelah pengumpulan data baik primer maupun sekunder sudah dianggap lengkap dan valid, maka dilakukan analisis guna mendapatkan kondisi yang sebenarnya. 


\section{Keluaran (output)}

Pada tahap ini merupakan tahap akhir yang meliputi tindak lanjut dari hasil analisis data, yang selanjutnya dituangkan dalam bentuk kesimpulan dan saran atau rekomendasi.

\section{B. Metode Pengumpulan Data}

Pengumpulan data meliputi pengumpulan data sekunder yang diperoleh dari instansi terkait seperti Dinas Perhubungan Pemerintah Kabupaten Bekasi dan Polres Bekasi, yang meliputi :

1. Jumlah sepeda motor yang terdaftar di Kabupaten Bekasi.

2. Jumlah pelanggaran lalu lintas oleh Pengemudi sepeda motor.

3. Jumlah Kecelakaan dan Korban Kecelakaan Lalu Lintas di Bekasi.

4. Jumlah Kecelakaan dan Korban Kecelakaan Lalu Lintas di Indonesia.

Sedangkan data primer merupakan hasil survei yang akan dilakukan terhadap pengemudi sepeda motor, yang meliputi :

1. Pengetahuan dan pemahaman pengendara sepeda motor terhadap APILL, rambu lalu lintas, dan marka jalan.

2. Tingkah laku pengendara sepeda motor selama berkendara.

3. Ketaatan dan kepatuhan terhadap APILL, rambu-rambu lalu lintas, dan marka jalan.

4. Cara memperoleh SIM C.

\section{Variabel}

Dalam penelitian ini terdapat dua variabel, yakni variabel bebas dan variabel terikat.Variabel bebas terdiri dari variabel $\left(\mathrm{X}_{1}, \mathrm{X}_{2}\right.$, dan $\left.\mathrm{X}_{3}\right)$, sedangkan variabel terikatnya terdiri dari satu veriabel (Y).

Adapun faktor-faktor yang ditetapkan sebagai variabel dalam penelitian ini sebagai berikut:

1. Variabel bebas $\left(\mathrm{X}_{1}\right)$ : Pengetahuan mengenai APILL, rambu lalin, dan marka jalan.

2. Variabel bebas $\left(\mathrm{X}_{2}\right)$ : Tingkah laku pengemudi sepeda motor.

3. Variabel bebas $\left(\mathrm{X}_{3}\right)$ : Cara memperoleh SIM C.

4. Variabel terikat (Y) : Keselamatan. 


\section{Metode Analisis}

Metode analisis yang digunakan adalah dengan menganalisis pengetahuan dan pemahaman pengendara sepeda motor terhadap APILL, rambu lalu lintas, dan marka jalan. Kemudian tingkah laku pengendara sepeda motor selama berkendara. Di samping itu juga menganalisis ketaatan dan kepatuhan terhadap APILL, rambu lalu lintas, marka jalan dan cara memperoleh SIM C, serta analisis kinerja operasional keselamatan Pengemudi Sepeda Motor, dengan bantuan statistik menggunakan metode deskriptif dan analisis hubungan (korelasi).

Dari hasil kuesioner yang diperoleh, dijumlahkan, maka akan memperoleh skor responden terhadap variabel bebas $\mathrm{X}_{1}, \mathrm{X}_{2}$, dan $\mathrm{X}_{3}$ yang dilambangkan sebagai Sigma $\mathrm{X}_{1}, \mathrm{X}_{2}$, dan $\mathrm{X}_{3}$ $\left(\Sigma \mathrm{X}_{1} \& \Sigma \mathrm{X}_{2} \& \Sigma \mathrm{X}_{3}\right)$.

Nilai tersebut kemudian akan dimasukan dalam worksheet statistik yang digunakan untuk mengukur pengaruh masing-masing variabel $\left(\mathrm{X}_{1}, \mathrm{X}_{2}\right.$, dan $\left.\mathrm{X}_{3}\right)$ terhadap variabel $\mathrm{Y}$, dan dapat diketahui seberapa besar kontribusi pengaruh variabel-variabel tersebut terhadap variabel keselamatan.

Dalam penelitian ini, digunakan Analisis Regresi Linear Berganda.Analisis regresi linier berganda digunakan untuk mengukur pengaruh dua atau lebih variabel independen (Imam Ghazali, 2013).

\section{Uji F}

Untuk mengetahui ada atau tidaknya pengaruh simultan (bersama-sama) yang diberikan variable bebas $(\mathrm{X})$ terhadap varibel terikat $(\mathrm{Y})$ maka dilakukan uji $\mathrm{F}$, dengan metode Uji ANOVA.

\section{Uji t}

Uji " $t$ " adalah pengujian signifikan parsial atau individual yang digunakan untuk menganalisis apakah variabel independen secara individual berpengaruh terhadap variabel dependen (Imam Ghozali : 2011). 
J. Bagan Alur Penelitian

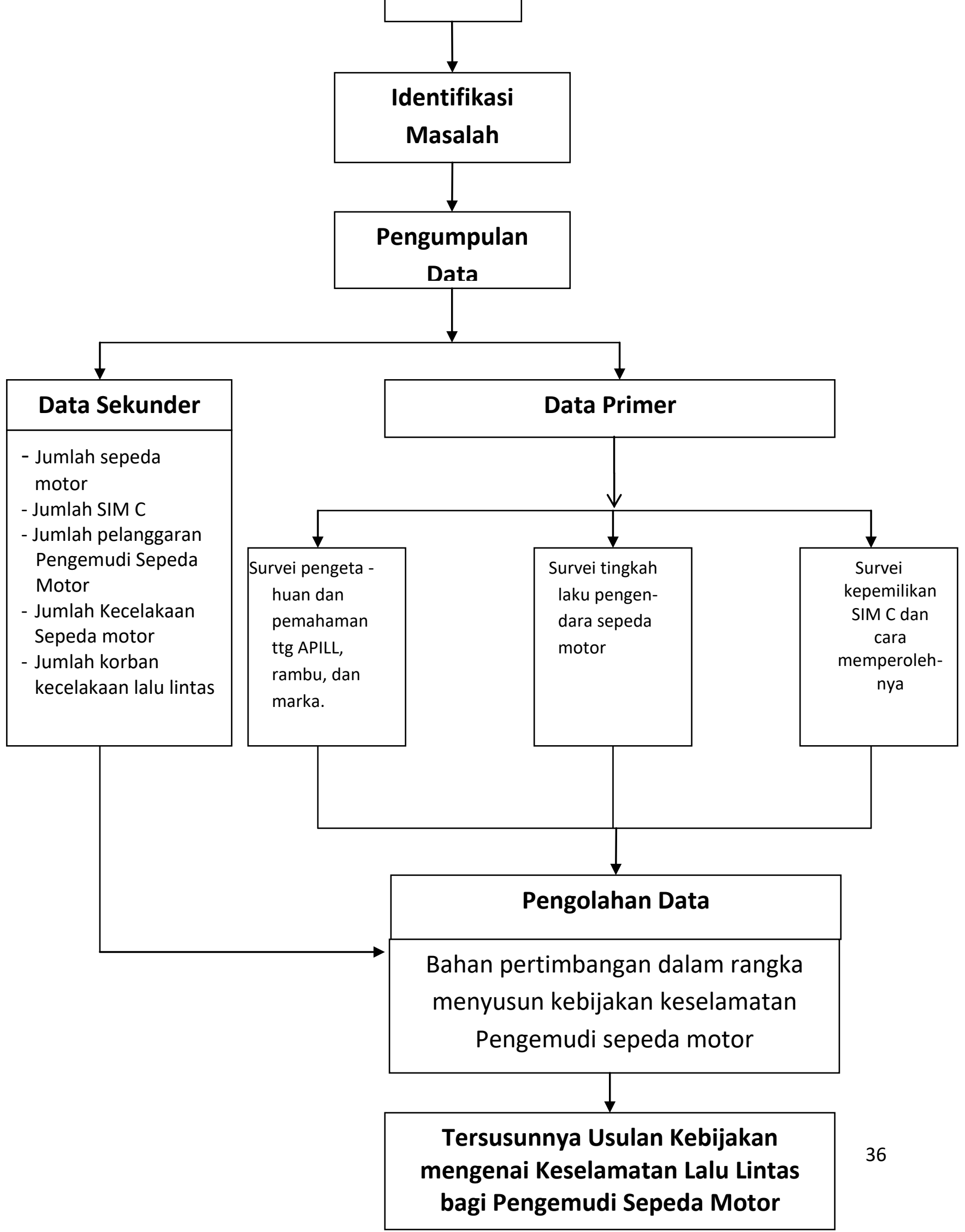




\section{PENGOLAHAN DATA DAN ANALISIS}

\section{Jumlah Sepeda Motor Yang Terdaftar di DKI Jakarta dan di Kabupaten Bekasi}

Sepada motor yang dikeluarkan dan terdaftar di DKI Jakarta dari tahun 2013 hingga tahun 2017 terjadi peningkatan, yaitu dari jumlah 10.333.025 unit menjadi 15.502.276 unit, terjadi peningkatan rata-rata 9,36\%. Sedangkan untuk sepeda motor yang terdaftar di Kabupaten Bekasi dari tahun 2015 hingga 2017 juga terjadi peningkatan, yaitu dari 1.045.000 unit menjadi 1.316.457 unit, terjadi peningkatan rata-rata $10,8 \%$. Untuk krdua wilayah tersebut jika dibandingkan peningkatannya lebih besar di Kabupaten Bekasi.Untuk lebih jelasnya dapat dilihat pada Tabel berikut ini.

Tabel Jumlah Sepeda Motor Yang Terdaftar di DKI Jakarta

\begin{tabular}{|c|c|c|c|}
\hline Tahun & Jumlah (Unit) & Pertumbuhan (\%) & Keterangan \\
\hline 2013 & 10.333 .025 & - & \\
\hline 2014 & 13.100 .000 & $21,12 \%$ & \\
\hline 2015 & 13.980 .000 & $6,29 \%$ & \\
\hline 2016 & 14.600 .000 & $4,23 \%$ & \\
\hline 2017 & 15.502 .276 & $5,82 \%$ & Rata-rata 9,36\% \\
\hline
\end{tabular}

Sumber : Ditlantas Polda Metro Jaya

Tabel Jumlah Sepeda Motor Yang Terdaftar di Kabupaten Bekasi

\begin{tabular}{|c|c|c|c|}
\hline Tahun & $\begin{array}{c}\text { Jumlah } \\
\text { (Unit) }\end{array}$ & $\begin{array}{c}\text { Pertumbuhan } \\
\text { (\%) }\end{array}$ & Keterangan \\
\hline 2015 & 1.045 .000 & - & \\
\hline 2016 & 1.231 .699 & $15,16 \%$ & \\
\hline 2017 & 1.316 .457 & $6,44 \%$ & Rata-rata 10,8\% \\
\hline
\end{tabular}

Sumber : Pikiran Rakyat 22 September 2017, Buku Statistk Transportasi DKI Jakarta 2015, dan Republika 25 November 2017 


\section{A. Jumlah Kecelakaan Lalu Lintas di Indonesia}

Untuk lebih jelasnya jumlah kasus dan jumlah korban kelakaan lalu lintas dari tahun 2014 hingga tahun 2017 dapat dilihat pada Tabel 5.4 berikut.

Jumlah Kecelakaan Lalu Lintas di Indonesia

\begin{tabular}{|c|c|c|c|c|}
\hline Tahun & Kasus & $\begin{array}{c}\text { Korban } \\
\text { (orang) }\end{array}$ & $\begin{array}{c}\text { Kerugian Materi } \\
\text { (Rp) }\end{array}$ & Keterangan \\
\hline 2014 & 95.906 & - & - & \\
\hline 2015 & 98.970 & - & 272,00 milyar & \\
\hline 2016 & 105.374 & 258.775 & 229,13 milyar & \\
\hline 2017 & 98.419 & 249.763 & 210,30 milyar & \\
\hline
\end{tabular}

Sumber : Korlantas Polri

1. Tingkah Laku Pengemudi Sepeda Motor $\left(\mathrm{X}_{2}\right)$

Perhitungan variabel bebas $\mathrm{X}_{2}$ dengan responden 150 orang, menggunakan rumus sebagai berikut :

$$
\begin{aligned}
& X_{2}=\frac{(a+b+c+d+e+f)}{6} \\
& =\frac{(86+65+101+119+102+98)}{-6}=\mathbf{9 5}(\mathbf{6 3} \%)
\end{aligned}
$$

2. Cara memperoleh SIM C $\left(\mathrm{X}_{3}\right)$

Penghitungan variabel bebas $\mathrm{X}_{3}$ dengan responden 170 orang, menggunakan rumus sebagai berikut :

$$
\mathrm{X}_{3}=\mathrm{N}=\mathrm{a}+\mathrm{b}=170=49+121=121(\mathbf{7 2} \%)
$$


3. Dari penghitungan variabel bebas tersebut, diperoleh bahwa :
a. Pengetahuan mengenai APILL, Rambu Lalu Lintas, dan Marka Jalan $\left(\mathrm{X}_{1}\right)$ sebesar $121(70 \%)$.
b. Tingkah Laku Pengemudi Sepeda Motor $\left(\mathrm{X}_{2}\right)$ sebesar 95 (63 \%).
c. Cara memperoleh SIM C $\left(\mathrm{X}_{3}\right)$ sebesar 121 (72 \%).

\section{KESIMPULAN DAN SARAN}

\section{A. Kesimpulan}

Berdasarkan hasil analisis dan pembahasan pada bab-bab sebelumnya dapat disimpulkan bahwa :

a. Pengendara sepeda motor yang mengetahui mengenai APILL, rambu lalu lintas, dan marka jalan, dengan responden 175 orang, baru sebanyak 121 orang atau $\mathbf{7 0 \%}$;

b. Pengendara sepeda motor yang bertingkah laku baik pada saat berkendara dari responden sebanyak 150 orang, baru sebanyak 95 orang atau 63\%;

a. Pengendara sepeda motor yang mendapatkan SIM C sesuai prosedur dari responden sebanyak 170 orang, baru sebanyak 121 orang atau $\mathbf{7 2 \%}$.

b. Pengetahuan tentang berlalu lintas dan perlengkapan jalan (APILL, rambu Lalu lintas, dan marka jalan)- $\mathrm{X}_{1}$, dan perilaku pengguna sepeda motor $\left(\mathrm{X}_{2}\right)$, dari hasil analisis ternyataberkaitan dengan tingkat keselamatan bagi pengendara sepeda motor, karena konstanta sebesar 10,280 menyatakan bahwa jika variabel independen dianggap konstan, maka keselamatan berkendara (Y) sebesar 10,280. Koefisien regresi Pengetahuan Pengedara Motor $\left(\mathrm{X}_{1}\right)$ sebesar 0,197 artinya jika variabel independen lain nilainya tetap dan keselamatan berkendara mengalami kenaikan sebesar 1 persen, maka variabel keselamatan berkendara (Y) mengalami peningkatan sebesar 19,7 \%. Untuk cara memperoleh SIM C $\left(\mathrm{X}_{3}\right)$, dari hasil analisis ternyata tidak sinigfikan pengaruhnya terhadap keselamatan bagi pengendara sepeda motor. 


\section{B. Saran}

1. Sosialisasi tentang pengetahuan perlengkapan lalu lintas (APILL, rambu lalu lintas, dan marka jalan), etika dan tata cara berlalu lintas, perlu terus dilakukan kepada para pengguna kendaraan bermotor dalam rangka meningktan keselamatan di jalan.

2. Perlunya terus dilakukan penelitian berkaitan dengan faktor-faktor lain yang mempengaruhi tingkat keselamatan berlalu lintas, karena selain faktor manusia ada faktor sarana dan prasana serta lingkunagn yang ikut berkontribusi dalam kecelakaan lalu lintas.

3. Dalam pemberian SIM C khususnya, perlu meningkatkan pengetahuan mengenai rambu lalu lintas dan marka jalan sebagaimana telah diatur oleh peraturan perundang-undangan.

\section{DAFTAR PUSTAKA}

Fidel Miro, Pengantar Sistem Transportasi, Penerbit Erlangga, Jakarta, 2012

Haryo Satmiko, ATD, S.Sos, M.Pd, Keselamatan Transportasi, Penerbit PT

RajaGrafindo Persada, Depok, Cetakan ke-1, April 2018.

Jalius Jama, Prof, Dr, M.Ed, dkk, Buku Teknik Sepeda Motor Mobile-Friedly, Penerbit

Pusat Perbukuan Departemen Pendidikan Nasional, Jakarta,2008.

Sutiman dan Moch. Solihin, Buku Mesin Sepeda Motor, Penerbit UNY, Jakarta.

Sumarsono, Sony, HM, Metude Riset Sumber Daya Manusia, Graha Ilmu, Yogyakarta, 2004.

Kabupaten Bekasi Dalam Angka 2013, Bekasi, 2013.

BPS Provinsi DKI Jakarta, Statistik Transportasi DKI Jakarta 2015, Jakarta, 2015

Direktorat Jenderal Perhubungan Darat, Departemen Perhubungan, 2009, Undang-undang Republik Indonesia No. 22 Tahun 2009 Tentang Lalu lintas dan Angkutan Jalan, Jakarta.

Direktorat Jenderal Perhubungan Darat, Kementerian Perhubungan, 2012, Peraturan Pemeritah Republik Indonesia Nomor 55 Tahun 2012 Tentang Kendaraan, Jakarta. 